\title{
Increasing the degree of nepheline raw materials use based on the conversion of sludge from alumina production
}

\author{
M.A. Gorbachev \\ Postgraduate student, Saint-Petersburg Mining University, Saint-Petersburg, Russia \\ V.M. Sizyakov \\ Professor, Metallurgy Department, Saint-Petersburg Mining University, Saint-Petersburg, Russia \\ R.V. Kurtenkov \\ PhD, Associate professor, Saint-Petersburg Mining University, Saint-Petersburg, Russia
}

I.S. Bormotov

Student, Saint-Petersburg Mining University, Saint-Petersburg, Russia

\begin{abstract}
A modern approach to metallurgical production requires the implementation of technological solutions to reduce the amount of waste generated. The possibility of processing nepheline sludge into a calcareous component by means of combined conversion is proposed. The product of sludge disposal in this case is calcium carbonate, silica gel and soda solution. The developed methods for processing nepheline sludge are simple, low cost of implementation and can be carried out on typical equipment for alumina production, that will allow to diversify production. The described approach allows to increase the economic efficiency of production.
\end{abstract}

\section{INTRODUCTION}

Modern metallurgical production is characterized by the use of technologies that ensure the extraction of a significant amount of valuable components in the processing of ore raw materials of natural and technogenic origin. At the same time, low-value impurity components and minerals of waste rock are released into the sludge products in their original or chemically modified form, followed by storage in sludge storages (Lainer 1961, Eremin et al. 1980). Currently, these processes are on a global scale, which pose a serious problem for the industrial and environmental safety of existing enterprises and adjacent territories. This problem is especially acute in relation to the processing of aluminum-containing raw materials (ElDeeb et al. 2019, Sizyakov et al. 2016, Brichkin et al. 2019). For example, in the processing of bauxite per 1 ton of the final product (aluminum), at least 2 tons of waste sludge is formed, and in the processing of nepheline, this amount is already 12 or more tons, depending on the quality of the feedstock. The existing integrated method of processing nepheline into alumina and associated products allows the disposal of nepheline sludge in the production of cement and cementitious components, however, in the current situation in the market of building materials and the economic inexpediency of transporting cement over long distances leads to the accumulation of solid waste in sludge storages Figure 1.

Thus, it is of interest to develop a cost-effective technology aimed at separating the calcareous component into an independent product with its subsequent application in the alumina production cycle, obtaining products of the carboaluminate series for the chemical industry and the production of materials with high added value. 
a)

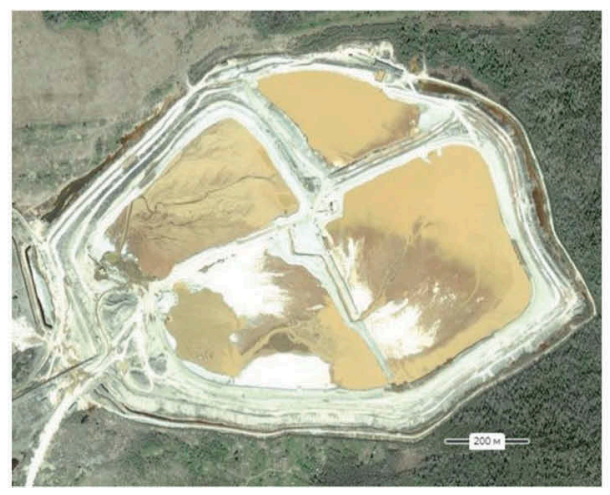

b)

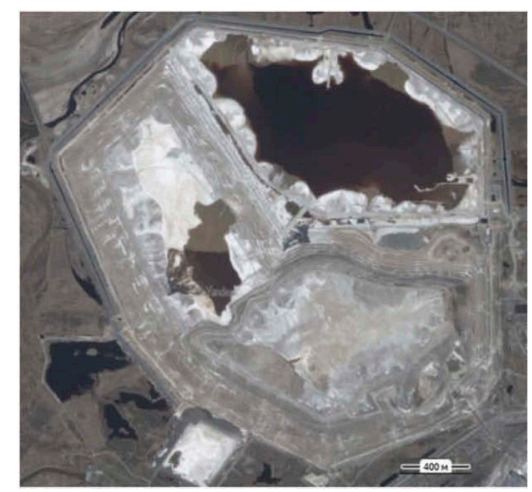

Figure 1. Sludge storage facilities for alumina refineries in Pikalevo (a) and Achinsk (b).

\section{MATERIALS AND RESEARCH METHODS}

Nepheline sludge is a multicomponent system, the composition of which depends on the chemical interactions during sintering, leaching of nepheline concentrate and subsequent washing, the chemical composition of the sludge is presented in Table 1 . The solid waste obtained during production has a physical density of $3150-3200 \mathrm{~kg} / \mathrm{m} 3$, bulk density in the range of $1000-1500 \mathrm{~kg} / \mathrm{m} 3$. According to its mineralogical composition, it is $80 \%$ composed of $\beta$-modification of dicalcium silicate (belite).

In the works of P.I. Bozhenov (Bozhenov \& Kavalerova 1966), the dependence of the activity of dicalcium silicate $\mathrm{C}_{2} \mathrm{~S}$ in the nepheline sludge on the alkaline module (molar ratio $\mathrm{R}_{2} \mathrm{O}: \mathrm{Al}_{2} \mathrm{O}_{3}$ ) of the nepheline-limestone charge was determined. This dependence is shown in Figure 2.

Thus, taking into account the production requirements for the alkaline module of the nepheline-limestone charge, it can be concluded that the activity obtained at the Russian production facilities of nepheline sludge is in the optimal region for its processing. At the same time, it should be remembered that in the production of alumina from nepheline, one of the key tasks of sintering is the binding of silicon to dicalcium silicate in the form of a low-active $\beta$ modification $\left(\beta-\mathrm{C}_{2} \mathrm{~S}\right)$. In turn, $\alpha$-modification is more preferable and would greatly simplify the processing of sludge due to its activity, but this solution is not practical, since it will lead to significant contamination of aluminate solutions during leaching, and additional heat treatment of the sludge to transfer dicalcium silicate from $\beta$-modification to the $\alpha$-modification is economically disadvantageous, since it requires heating the material. Therefore, comprehensive approaches to hydrochemical treatment are needed, which make it possible to utilize nepheline sludge without additional heat treatment.

The fundamental possibility of the soda-carbon dioxide conversion of nepheline sludge to calcium carbonate and the separation of silicon in the form of a silicate solution was previously shown and are associated with the thermodynamic instability of calcium silicates formed under high-temperature sintering processes in relation to hydration, hydrolysis, and ion exchange (Abramov et al. 1990, Shmorgunenko \& Korneev 1982). Soda and carbon dioxide conversion is characterized by the following stoichiometric ratios, respectively:

$$
\mathrm{Ca}_{2} \mathrm{SiO}_{4}+2 \mathrm{Na}_{2} \mathrm{CO}_{3}=2 \mathrm{CaCO}_{3}+\mathrm{Na}_{4} \mathrm{SiO}_{4}
$$

Table 1. The chemical composition of nepheline sludge, \% (mass.) (Abramov et al. 1990).

\begin{tabular}{llllllll}
\hline Refinery & Loss on calcination & $\mathrm{SiO}_{2}$ & $\mathrm{Al}_{2} \mathrm{O}_{3}$ & $\mathrm{Fe}_{2} \mathrm{O}_{3}$ & $\mathrm{CaO}$ & $\mathrm{R}_{2} \mathrm{O}$ & Others \\
\hline Pikalevo & 2,6 & 29,6 & 2,6 & 3,0 & 56,8 & 1,8 & 3,6 \\
Achinsk & 3,4 & 28,8 & 4,2 & 3,6 & 54,6 & 2,6 & 2,8 \\
\hline
\end{tabular}




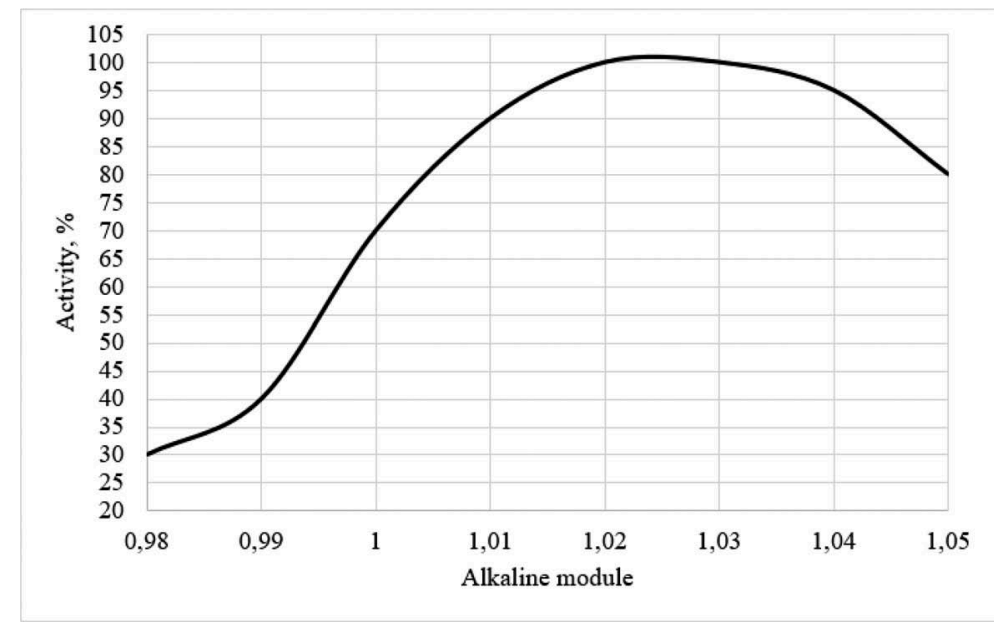

Figure 2. The dependence of the activity of $\mathrm{C}_{2} \mathrm{~S}$ in nepheline sludge on the alkaline module of charge.

$$
\begin{gathered}
\mathrm{Ca}_{2} \mathrm{SiO}_{4}+2 \mathrm{Na}_{2} \mathrm{CO}_{3}+\mathrm{H}_{2} \mathrm{O}=2 \mathrm{CaCO}_{3}+\mathrm{Na}_{2} \mathrm{SiO}_{3}+2 \mathrm{NaOH} \\
2 \mathrm{CaO} \cdot \mathrm{SiO}_{2}+2 \mathrm{CO}_{2}=2\left(\mathrm{CaO} \cdot \mathrm{CO}_{2}\right)+2 \mathrm{SiO}_{2} .
\end{gathered}
$$

However, the proposed methods and technical solutions do not allow a high degree of conversion and can be used mainly to obtain a single-component cement mixture, which necessitates further studies aimed at achieving the conversion of belite in the composition of nepheline sludge to $95-100 \%$, and increasing the efficiency and the complexity of its processing.

The main indicators of the soda conversion of nepheline sludge were determined in laboratory conditions using a factory sample of a nepheline sludge of an average composition and synthetic soda solutions. The chemical composition is presented in Table 1 .

\section{EXPERIMENTAL}

The methodology for experimental research includes the preparation of synthetic solutions of soda, repulpation of nepheline sludge with a soda solution with a given concentration (from $52,5-233,8 \mathrm{~g} / \mathrm{l}$ ) at a constant concentration of solid in the pulp, corresponding to Liquid: Solid $=1 \div 10$. The conversion was carried out in a single reactor AutoLAB system for $0,5-6$ hours. After completion of the process, the pulp was filtered off on a laboratory vacuum filter to obtain technological products. The liquid phase was analyzed for the content of total and caustic alkali by the titrimetric method in accordance with the accepted industry method and silicon dioxide by the photometric method. The degree of conversion was calculated by determining the carbonate carbon content in solid products by spectral analysis using a TOC-L analyzer.

During the experiment, the influence of various technological factors on the soda leaching of unmilled nepheline sludge (processing time, soda solution concentration) was studied. Graphic processing of the results of the study at the indicators of soda conversion of unmilled nepheline sludge $\mathrm{L}: \mathrm{S}=10$, process temperature $50-95^{\circ} \mathrm{C}$, the concentration of soda solution 52,5-233.8 g/l, is presented in Figures 3, 4.

The results obtained suggest that the temperature and concentration of soda solution are factors that have a significant effect on the change in the phase and chemical composition of the products. The dependence of the degree of conversion on the concentration of soda solution reflects the effects of stoichiometric, kinetic and thermodynamic nature. The shape of the kinetic curves suggests a noticeable diffusion inhibition of the conversion of belite, presumably due to 


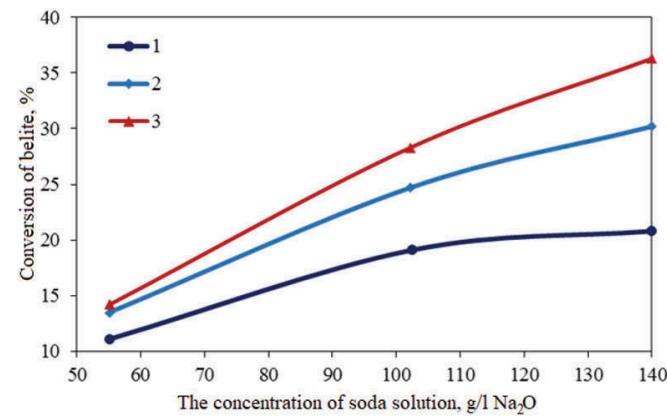

Figure 3. Effect of soda solution concentration on the decomposition of unmilled sludge at various temperatures: $1-50^{\circ} \mathrm{C}, 2-75^{\circ} \mathrm{C}, 3-95^{\circ} \mathrm{C}$.

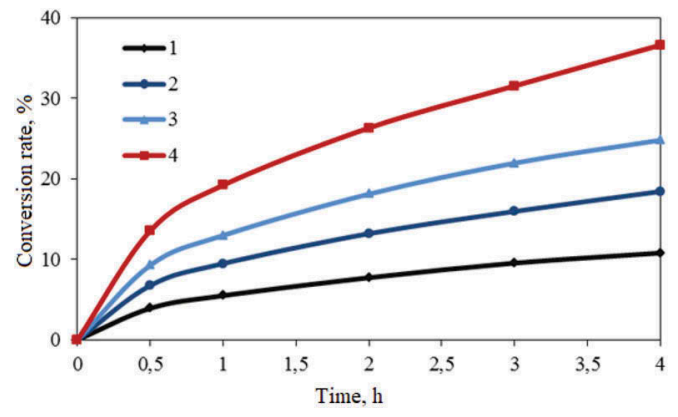

Figure 4. Kinetics of soda conversion of unmilled nepheline sludge at a temperature of $95{ }^{\circ} \mathrm{C}$ and a concentration of $\mathrm{Na}_{2} \mathrm{CO}_{3}: 1-52,5 \mathrm{~g} / 1,2-110,3$ $\mathrm{g} / \mathrm{l} ; 3$ - 187,1 g/l; 4 - 233,8 g/l.

the formation of solid products on the surface of the initial solid phase. The calculated values of the Pilling-Bedwards test for conversion products by reactions (1) and (2) are 1,27 and 1,33, which also indicates the possibility of the formation of stable passivating films.

To intensify the conversion process and achieve higher values, an experiment was carried out for a three-stage hydrochemical treatment of nepheline sludge based on the transition to the region of pearsonite $\left(\mathrm{Na}_{2} \mathrm{CO}_{3} \cdot \mathrm{CaCO}_{3} \cdot 2 \mathrm{H}_{2} \mathrm{O}\right)$ formation using soda solutions with a $\mathrm{Na}_{2} \mathrm{O}$ concentration of more than $220 \mathrm{~g} / \mathrm{l}$ according to the reaction:

$$
\mathrm{CaCO}_{3}+\mathrm{Na}_{2} \mathrm{CO}_{3}+2 \mathrm{H}_{2} \mathrm{O}=\mathrm{Na}_{2} \mathrm{CO}_{3} \cdot \mathrm{CaCO}_{3} \cdot 2 \mathrm{H}_{2} \mathrm{O}
$$

To carry out the research, a laboratory setup based on the AutoLAB single-reactor system was assembled (Figure 5). The experimental design is shown in Figure 6.

The selection of technological parameters and processing methods was carried out on the basis of the analysis of scientific and technical literature in the field of processing of nepheline

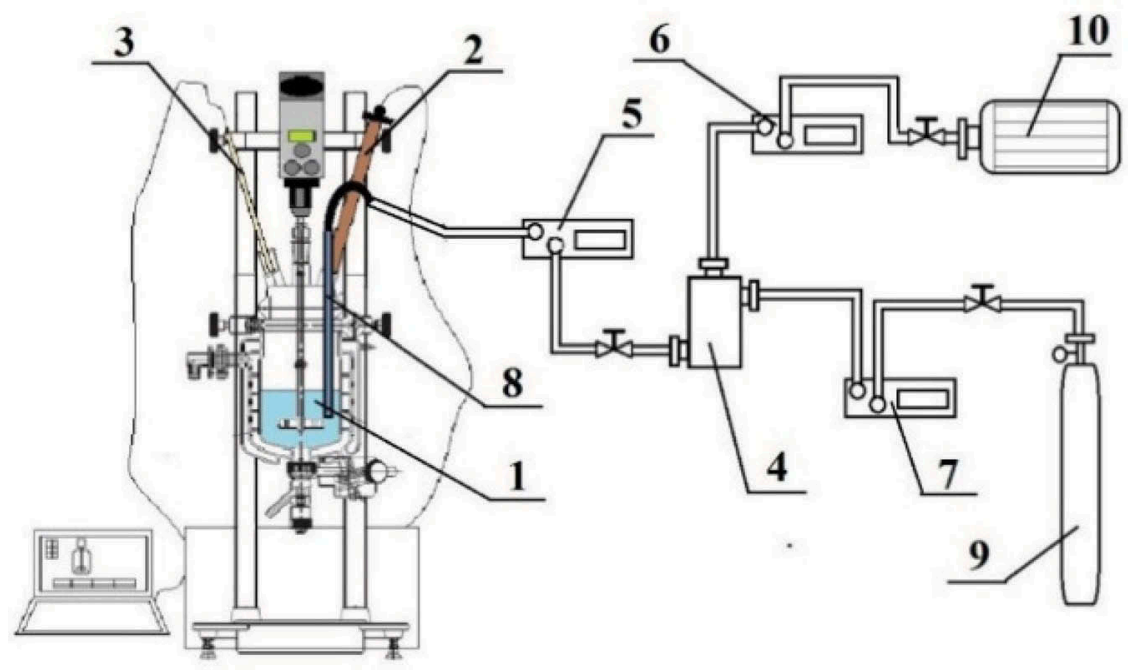

Figure 5. Scheme of a laboratory setup for a three-stage hydrochemical treatment. 1 - steel reactor 2,0 1. Single reactor AutoLab system (HEL); 2- pH electrode; 3 - temperature sensor; 4 - gas mixer; 5, 6, 7 gas meter RGS-1; 8 - gas supply pipe; 9 - a cylinder with technical carbon dioxide; 10 - compressor. 


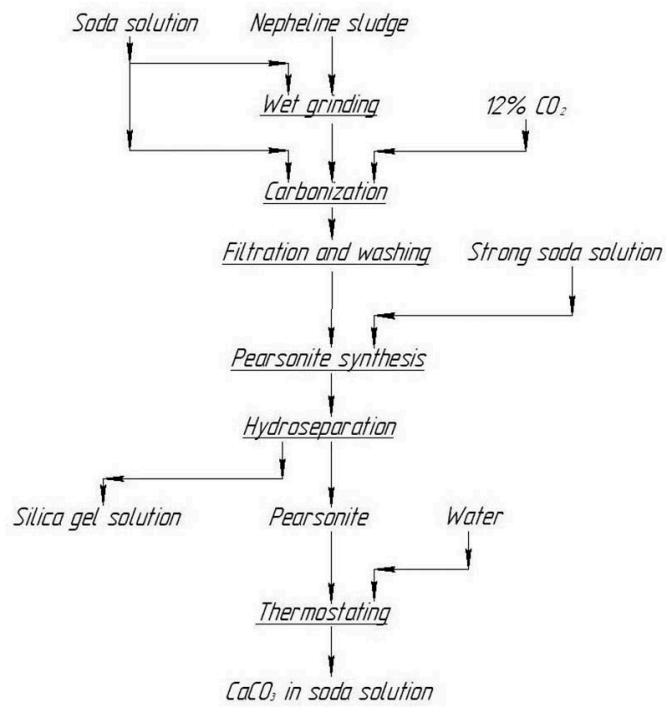

Figure 6. Scheme of the experiment.

and its sludges. In order to intensify the decomposition process, mechanical activation of nepheline sludge particles in a ball mill Pulverisette 6 (Fritsch) is built into the beginning of the scheme. As a result of the action of the balls and soda solution, the particles of the sludge are destroyed (hence, the increase in the reaction surface) and the process of its decomposition by reaction 1 begins. Wet grinding was carried out with the ratio $\mathrm{L}: \mathrm{S}=1$. After grinding, the size of the sludge corresponded to the residue on a sieve of $80 \mu \mathrm{m}-5-6 \%$. The concentration of soda solution during grinding was $120 \mathrm{~g} / \mathrm{l} \mathrm{N} \mathrm{N}_{2} \mathrm{O}$. After grinding, the suspension was brought with a soda solution with a concentration of $120 \mathrm{~g} / 1 \mathrm{Na}_{2} \mathrm{O}$ to the ratio $\mathrm{L}: \mathrm{S}=10$ in pulp and was sent for further carbonization at a temperature of $85^{\circ} \mathrm{C}$ for 5 hours. The composition of the gas phase corresponded to $12 \%$ vol. $\mathrm{CO}_{2}$, the flow rate of the gas mixture was maintained at $2.0 \mathrm{l} / \mathrm{min}$. At this stage, the formation of the first pearsonite crystals, which subsequently at the stage of synthesis, act as seeds.

Due to inactivity of stale nepheline sludge, it was determined that a precondition for the creation of a working scheme is pearsonite transformation, i.e. transition of the calcareous component to the double carbonate salt state according to reaction 4 . The main reason for this solution is the need to separate the calcareous component from the silica gel solution. For this, at the second stage, the obtained slurry after washing was subjected to additional treatment with a strong soda solution with a concentration of $220 \mathrm{~g} / 1 \mathrm{Na}_{2} \mathrm{O}$ for 6 hours at $\mathrm{L}: \mathrm{S}=4$ and a temperature of $90{ }^{\circ} \mathrm{C}$. Due to this operation, the synthesis of pearsonite in the field of its stable state is carried out. Then, the resulting pulp was separated on a laboratory vacuum filter and the solid phase was washed.

The third stage of the experiment consisted in thermostating of the solid residue in water to go into the region of metastable state of pearsonite and its decomposition to produce calcium carbonate and soda solution.

According to the results of the experiment, the resulting material was analyzed for inorganic carbon using a TOC-L analyzer. The calculated degree of conversion was $72 \%$, a rather low rate is associated with incomplete decomposition of sludge, however, it shows the possibility of their processing by the considered method. Additional confirmation that during the conversion of nepheline sludge decomposes pearsonite with the formation of calcium carbonate and alkali is the result of a titrimetric analysis of the solution after filtration to total alkali which showed an alkali content of $130 \mathrm{~g} / \mathrm{l}$. 


\section{CONCLUSION}

The results showed the fundamental possibility of modifying nepheline sludges to produce a calcareous component. Further research should be aimed at studying the influence of the parameters of mechanochemical activation of nepheline sludge, the processes of carbonization and synthesis of pearsonite to achieve a degree of nepheline sludge conversion at the level of $95-100 \%$. Presumably, an increase in the concentration of soda solution and the time of the carbonization process will increase the degree of decomposition of nepheline sludge due to a deeper hydrochemical preparation for the synthesis of pearsonite. The gas mixture used in the experiment in terms of carbon dioxide content is similar to the composition of the exhaust gases from sintering furnaces, which reduces the emission of carbon dioxide into the environment.

The application of this approach allows to increase the economic efficiency of the technology by obtaining new products, as well as reducing the cost of measures to protect the environment from the effects of industrial wastes.

\section{ACKNOWLEDGMENTS}

The study was carried out with the financial support of the Ministry of Education and Science of the Russian Federation (registration number of the project 11.4098.2017/ПЧ of 01.01.2017).

\section{REFERENCES}

Abramov, V.Y. \& Alekseev, A.I. \& Badalyants, Ch.A. 1990. Complex processing of apatite-nepheline raw materials. Moscow: Metallurgy.

Bozhenov, P.I. \& Kavalerova, V.I. 1966. Nepheline sludges. Moscow: Stroyizdat.

Brichkin, V.N. \& Kurtenkov, R.V. \& ElDeeb, A.B. \& Bormotov, I.S. 2019. State and development options for the raw material base of aluminium in non-bauxite regions. Obogashchenie Rud 4: 31-37. St.-Petersburg: Ore\&Metals.

ElDeeb, A.B. \& Brichkin, V.N. \& Kurtenkov, R.V. \& Bormotov, I.S. 2019. Extraction of alumina from kaolin by a combination of Pyro- and hydrometallurgical Processes. Applied Clay Science 172: 146-154. Amsterdam: Elsevier Science Publishing Company, inc.

Eremin, N.I. \& Naumchik, A.N. \& Kazakov, V.G. 1980. Processes and apparatuses of alumina production. Moscow: Metallurgy.

Lainer A.I. 1961. Alumina production. Moscow: Metallurgy.

Shmorgunenko N.S. \& Korneev V.I. 1982. Complex processing and use of slime dump alumina production, Moscow: Metallurgy.

Sizyakov, V.M. \& Brichkin, V.N. \& Kurtenkov, R.V. 2016. Increasing all-round utilization of nepheline raw materials through belite sludge soda conversion. Obogashchenie Rud 1: 54-59. St.-Petersburg: Ore\&Metals. 